The model of sol id phase crystal I ization of anor phous si li con under el ast i c stress

\begin{tabular}{|l|l|}
\hline 著者 & K mur a Yasuo, Ki shi Nasat o, Kat oda Takashi \\
\hline $\begin{array}{l}\text { j our nal or } \\
\text { publ i cat i on ti t l e }\end{array}$ & Journal of Appl i ed Physi cs \\
\hline vol une & 87 \\
\hline number & 8 \\
\hline page r ange & $4017-4021$ \\
\hline year & $2000-0415$ \\
\hline URL & ht t p: //hdl . handl e. net /10173/798 \\
\hline
\end{tabular}




\section{AIP Applited Physics}

\section{The model of solid phase crystallization of amorphous silicon under elastic stress}

Yasuo Kimura, Masato Kishi, and Takashi Katoda

Citation: J. Appl. Phys. 87, 4017 (2000); doi: 10.1063/1.372448

View online: http://dx.doi.org/10.1063/1.372448

View Table of Contents: http://jap.aip.org/resource/1/JAPIAU/v87/i8

Published by the American Institute of Physics.

\section{Related Articles}

Transmission electron microscopy of the amorphization of copper indium diselenide by in situ ion irradiation J. Appl. Phys. 111, 053510 (2012)

Diffusion-controlled formation mechanism of dual-phase structure during Al induced crystallization of SiGe Appl. Phys. Lett. 100, 071908 (2012)

Local structure of nitrogen in N-doped amorphous and crystalline GeTe Appl. Phys. Lett. 100, 061910 (2012)

Facile creation of bio-inspired superhydrophobic Ce-based metallic glass surfaces Appl. Phys. Lett. 99, 261905 (2011)

How does spallation microdamage nucleate in bulk amorphous alloys under shock loading? J. Appl. Phys. 110, 103519 (2011)

\section{Additional information on J. Appl. Phys.}

Journal Homepage: http://jap.aip.org/

Journal Information: http://jap.aip.org/about/about_the_journal

Top downloads: http://jap.aip.org/features/most_downloaded

Information for Authors: http://jap.aip.org/authors

\section{ADVERTISEMENT}
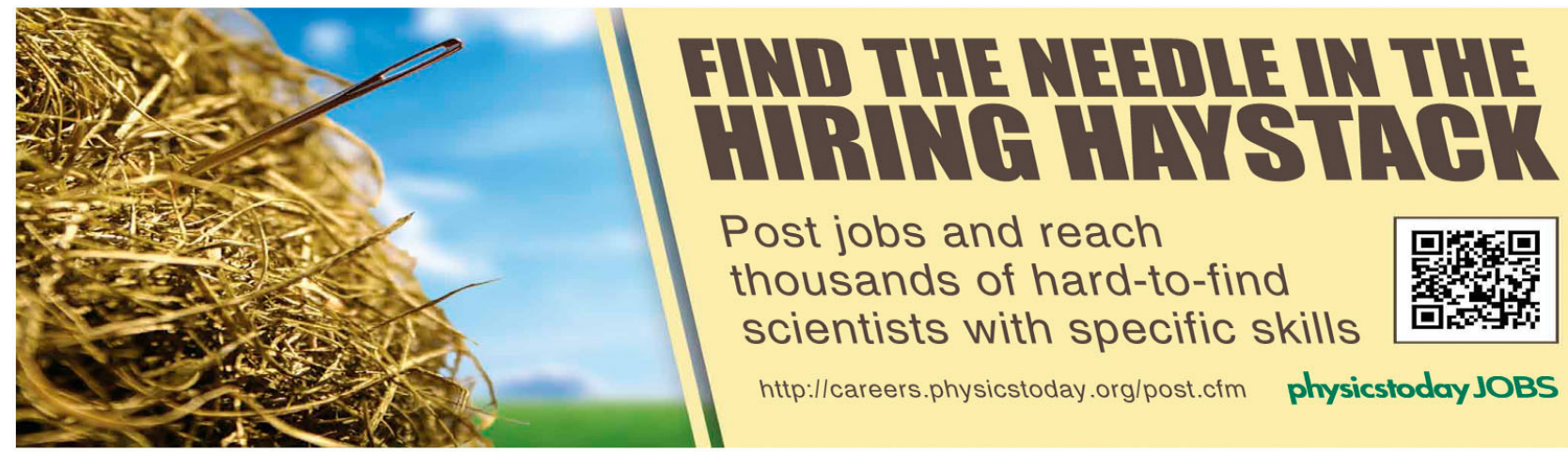


\title{
The model of solid phase crystallization of amorphous silicon under elastic stress
}

\author{
Yasuo Kimura a) and Masato Kishi \\ Department Electronic Engineering, Faculty of Engineering, The University of Tokyo, 7-3-1 Hongo, \\ Bunkyo-ku, Tokyo 113-8656, Japan \\ Takashi Katoda ${ }^{b)}$ \\ Faculty of Engineering, Kochi University of Technology, Tosayamada, Kochi 782-0003, Japan
}

(Received 22 February 1999; accepted for publication 17 December 1999)

\begin{abstract}
Solid phase crystallization of an amorphous silicon $(a-\mathrm{Si})$ film stressed by a $\mathrm{Si}_{3} \mathrm{~N}_{4}$ cap was studied by laser Raman spectroscopy. The $a$-Si films were deposited on $\mathrm{Si}_{3} \mathrm{~N}_{4}(50 \mathrm{~nm}) / \mathrm{Si}(100)$ substrate by rf sputtering. The stress in an $a$-Si film was controlled by thickness of a $\mathrm{Si}_{3} \mathrm{~N}_{4}$ cap layer. The $\mathrm{Si}_{3} \mathrm{~N}_{4}$ films were also deposited by rf sputtering. It was observed that the crystallization was affected by the stress in $a$-Si films introduced by the $\mathrm{Si}_{3} \mathrm{~N}_{4}$ cap layer. The study suggests that the elastic stress increases with crystallization due to the smaller elastic modulus of $a$-Si with respect to crystalline silicon $(c-\mathrm{Si})$. It is most reasonable to think that the elastic stress does not relax and that the elastic energy increased with crystallization because the elastic modulus of $a$-Si is smaller than that of $c$-Si. The experimental data was fitted by this model and the difference of the enthalpy $\Delta H_{\mathrm{ac}}$ between $a$-Si and $c$-Si which is the latent heat of crystallization obtained by the fitting showed good coincidence with the previously reported value. (C) 2000 American Institute of Physics.
\end{abstract} [S0021-8979(00)07606-4]

\section{INTRODUCTION}

Polycrystalline silicon (poly-Si) is an important material in the fabrication of very large-scale integrated circuits (VLSI) and driving circuits for liquid crystal displays. Solid phase crystallization of amorphous silicon $(a-\mathrm{Si})$ is one method to form a poly-Si film. Therefore, it is very important to have clear understanding of the mechanism in crystallization from $a-\mathrm{Si}$ to poly-Si, in order to control properties of a poly-Si film such as grain size, electric resistance, and thermal conductivity. However, the mechanism of crystallization of $a-\mathrm{Si}$ is not yet clear. Especially the effect of stress on crystallization of $a$-Si films has not been understood, although very large stress is introduced between the $a$-Si film and the glass substrate which is used due to difference in the thermal expansion coefficient between $\mathrm{Si}$ and glass. Stress discussed in previous reports is a plastic one though the large stress in $a$-Si film on a glass substrate is an elastic one. Therefore, it is important to clarify the effects of elastic stress on crystallization and to control it.

We have reported that the elastic stress in $a$-Si suppressed crystallization in $a$-Si films with the $\mathrm{Si}_{3} \mathrm{~N}_{4}$ cap layer. ${ }^{1}$ This phenomenon was opposite to that of the strainanneal method. A model to explain crystallization under elastic stress is required. The model of phase transformation induced by stress requires the assumption that the stress relaxes with phase transformation and the stress can be regarded as a driving energy. Metal was used as a sample in the research of the strain-anneal method and this assumption is well satisfied when the introduced strain is a very large

\footnotetext{
${ }^{a}$ Electronic mail: ykimura@riec.tohoku.ac.jp
}

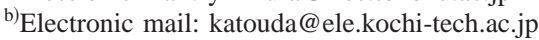

plastic one more than $\sim 1 \%$. However, both $a$-Si and crystal silicon $(c-\mathrm{Si})$ are nonmetallic and the introduced stress was elastic and very small. Therefore, the above assumption is not satisfied for crystallization from $a$-Si to poly-Si. It is more appropriate to assume that the introduced stress does not relax with crystallization and to regard the stress as the cause of suppression of crystallization in this condition.

In this work, the elastic stress in $a$-Si was controlled with a $\mathrm{Si}_{3} \mathrm{~N}_{4}$ cap and crystalline fractions were estimated from Raman spectra of poly-Si. The experimental data were fitted by our proposed model and the difference of the enthalpy between $a$-Si and poly-Si obtained by the fitting using our proposed model was compared with values reported by others.

\section{THEORY}

Helmholtz free energy in which strain energy is taken into account, $F$ is given by Helmholtz free energy without strain, $F_{0}$ and strain energy $E_{\text {strain }}$

$$
F=F_{0}+E_{\text {strain }} \text {. }
$$

The absolute value of the difference of between $c$-Si and $a-\mathrm{Si}, \Delta F$ is

$$
\Delta F=\left|F^{c-\mathrm{Si}}-F^{a-\mathrm{Si}}\right|=\Delta F_{0}-\Delta E_{\text {strain }},
$$

where $F^{a-\mathrm{Si}}$ and $F^{c-\mathrm{Si}}$ are Helmholtz free energies of $a$-Si and $c$-Si, respectively, $\Delta F_{0}$ is the absolute value of the difference of Helmholtz free energy in which strain energy is not taken into account, and $\Delta E_{\text {strain }}$ is the difference of strain energy between $c$-Si and $a-\mathrm{Si}$

$$
\Delta E_{\text {strain }}=E_{\text {strain }}^{c-\mathrm{Si}}-E_{\text {strain }}^{a-\mathrm{Si}} .
$$


$\Delta F$ is the driving energy of crystallization under stress. $\Delta E_{\text {strain }}$ can be positive, which means that $\Delta F$ is smaller than the driving energy $\Delta F_{0}$ under no stress condition. The crystallization occurs slowly when the introduced stress does not relax. When $\Delta F$ is larger than $\Delta F_{0}$ the introduced stress relaxes similar to the case of strain-anneal method because relaxation of stress $E_{\text {strain }}^{c-S i}=0$, that is, $\Delta E_{\text {strain }}<0$.

The nucleation rate $\dot{N}$ and the growth rate of a nucleus $u$ are given as follows, respectively:

$$
\begin{aligned}
& \dot{N} \propto \exp \left(-\frac{F_{a}+\Delta F_{r}^{*}}{k_{B} T}\right) \\
& u \propto \exp \left(-\frac{F_{a}}{k_{B} T}\right)\left\{1-\exp \left(-\frac{\Delta F}{k_{B} T}\right)\right\},
\end{aligned}
$$

where $F_{a}$ is the activation energy for the transfer of Si atoms from amorphous phase to crystal phase and $F_{a}$ $\gg E_{\text {strain }} . \Delta F_{r}^{*}$ is the energy necessary for the radius of a $c$-Si particle to grow larger than the critical radius $r^{*}$, and it is expressed as follows when the shape of a $c$-Si particle is a sphere,

$$
\Delta F_{r}^{*}=\frac{16 \pi \sigma^{3}}{3 \Delta F^{2}}
$$

In the assumption that the nucleation rate $\dot{N}$ and the growth rate $u$ are constant, the relation between crystallization time $t$ and crystalline fraction $\chi$ is described by

$$
\chi=1-\exp \left(-\frac{g \dot{N} u^{3}}{4} t^{4}\right),
$$

where $g$ is the shape factor $(4 / 3 \pi$ when the shape is a sphere). This is known as Johnson-Mehl's expression. ${ }^{2-5}$ It must be noted that this assumption is satisfied at the early stage of crystallization because the effective growth rate is small at this stage and the grains are in contact with each other. $g \dot{N} u^{3} / 4$ gives the crystallization speed at the early stage of the crystallization. $g \dot{N} u^{3} / 4$ is given by the gradient, when $x$ axis is $\ln (1-\chi)$ and $y$ axis is $t^{4}$ and is expressed using expressions (4)-(6),

$$
\frac{g \dot{N} u^{3}}{4} \propto \exp \left(-\frac{16 \pi \sigma^{3}}{3 \Delta F^{2} k_{B} T}\right)\left\{1-\exp \left(-\frac{\Delta F}{k_{B} T}\right)\right\}^{3} .
$$

\section{EXPERIMENT}

The absorption coefficient of light of an as-deposited $\mathrm{Si}_{3} \mathrm{~N}_{4}$ cap layer changed during annealing suggesting that the as-deposited $\mathrm{Si}_{3} \mathrm{~N}_{4}$ cap layer is unstable. The $\mathrm{Si}_{3} \mathrm{~N}_{4}$ cap layer was expected to be stable in order to control the stress in $a-\mathrm{Si}$ films. Therefore, all samples were annealed at $500{ }^{\circ} \mathrm{C}$ for $6 \mathrm{~h}$ in $\mathrm{Ar}+\mathrm{H}(6 \%)$ before crystallization at $750{ }^{\circ} \mathrm{C}$. The $\mathrm{Si}_{3} \mathrm{~N}_{4}$ cap layer annealed at $500^{\circ} \mathrm{C}$ for $6 \mathrm{~h}$ was stable and the following annealing at $750{ }^{\circ} \mathrm{C}$ did not change the absorption coefficient of the $\mathrm{Si}_{3} \mathrm{~N}_{4}$ cap. ${ }^{1}$

It is difficult to characterize stress based on a Raman spectrum from a poly-Si film because Raman shift depends not only on stress but also on grain size and crystallinity. Therefore, in order to characterize stress introduced by a

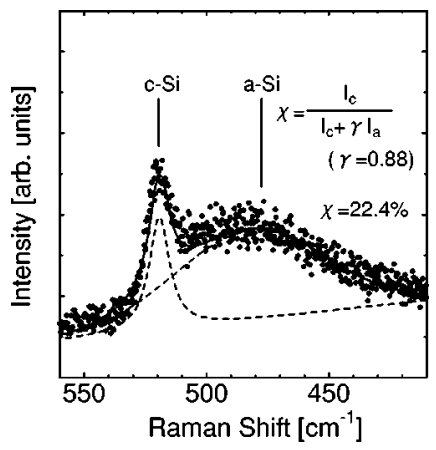

FIG. 1. Definition of crystalline fraction $\chi$. A typical Raman spectrum from poly-Si consists of two peaks, that is, one due to the crystal and the other due to $a$-Si. A crystalline fraction $\chi$ is defined by $I_{c} /\left(I_{c}+\gamma I_{a}\right)$ where $I_{c}$ and $I_{a}$ are areas of the peaks due to $c$-Si and $a$-Si, respectively, and $\gamma$ is a ratio of the scattering cross section.

$\mathrm{Si}_{3} \mathrm{~N}_{4}$ cap, the samples without the $a$-Si layer were prepared by rf sputtering and the structure was $\mathrm{Si}_{3} \mathrm{~N}_{4} / \mathrm{Si}(100)$. Stress introduced by a $\mathrm{Si}_{3} \mathrm{~N}_{4}$ cap was estimated from the extra peak shift which was the difference between the Raman peak position of a stressed $\mathrm{Si}(100)$ substrate and that of a stress-free $\operatorname{Si}(100)$ substrate about $520.5 \mathrm{~cm}^{-1}$. The peak shift to a higher wave number shows that compressive stress is introduced while the peak shift to a lower wave number shows that tensile stress is introduced. In the case of $\mathrm{Si}(100)$, the relation between an extra peak shift $\Delta \Omega\left[\mathrm{cm}^{-1}\right]$ and stress $\tau$ $\left[\mathrm{dyn} / \mathrm{cm}^{2}\right]$ is $\tau=-2.49 \Delta \Omega$, where $\tau<0$ means that the stress is compressive and $\tau>0$ means that the stress is tensile.

The stress introduced in the $a$-Si films was controlled by the thickness of the $\mathrm{Si}_{3} \mathrm{~N}_{4}$ cap layer. The structure of samples was $\mathrm{Si}_{3} \mathrm{~N}_{4} / a-\mathrm{Si}(1.5 \mu \mathrm{m}) / \mathrm{Si}_{3} \mathrm{~N}_{4}(50 \mathrm{~nm}) / \mathrm{Si}(100)$. All layers were deposited by rf sputtering at room temperature. The thickness of a $\mathrm{Si}_{3} \mathrm{~N}_{4}$ cap on an $a$-Si film was varied from 50 to $1000 \mathrm{~nm}$. The samples were annealed at $500{ }^{\circ} \mathrm{C}$ for $6 \mathrm{~h}$ in $\mathrm{Ar}+\mathrm{H}(6 \%)$ and then $a-\mathrm{Si}$ was transformed into poly-Si by further annealing at $750{ }^{\circ} \mathrm{C}$ in the same atmosphere. The crystallinity was characterized by laser Raman spectroscopy. The wavelength of the probe light was $514.5 \mathrm{~nm}$. The $\mathrm{Si}_{3} \mathrm{~N}_{4}$ cap was removed before the measurement of laser Raman spectroscopy because the Raman peak from $a$-Si is weak and broad. As, otherwise the $\mathrm{Si}_{3} \mathrm{~N}_{4}$ cap would absorb the probe light.

As shown in Fig.1, the crystalline fraction $\chi$ of poly-Si

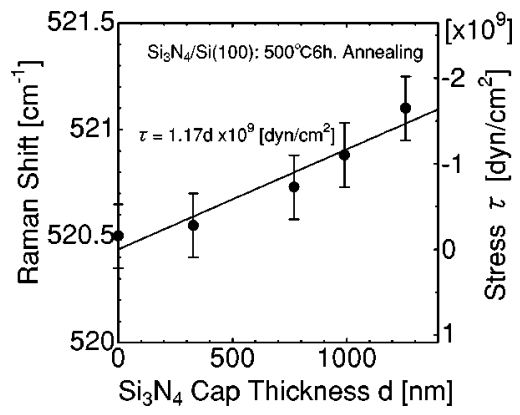

FIG. 2. Raman shift of $\mathrm{Si}(100)$ substrate stressed by a $\mathrm{Si}_{3} \mathrm{~N}_{4}$ cap. 


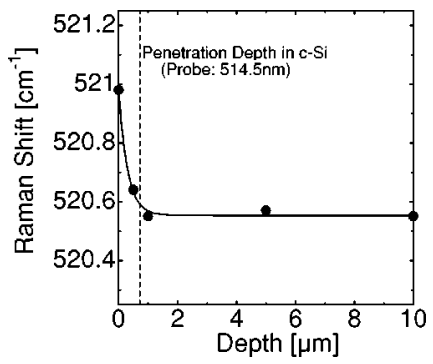

FIG. 3. The depth profile of stress in $\mathrm{Si}(100)$ substrate.

was obtained from a Raman spectrum using the following relation:

$$
\chi=\frac{I_{c}}{I_{c}+\gamma I_{a}},
$$

where $I_{c}$ and $I_{a}$ were the areas of the peaks of poly-Si and $a$-Si, respectively and $\gamma$ is the ratio of the scattering cross section. $\gamma$ varies with grain size and it is a very important factor in estimation of the crystalline fraction from a Raman spectrum. It has been reported that the value of $\gamma$ is 0.88 when grain size is small or crystalline fraction is small ${ }^{6}$ which corresponds to the early stage of crystallization. The early stage of crystallization is discussed in this study. Therefore, 0.88 was used as the value of $\gamma$ in this work. $I_{c}$ and $I_{a}$ were obtained by means of the least squares method assuming that a poly-Si peak and an $a$-Si peak were Lorenzian and Gaussian, respectively.

\section{RESULTS AND DISCUSSION}

Figure 2 shows Raman shift for $\mathrm{Si}(100)$ substrates stressed by a $\mathrm{Si}_{3} \mathrm{~N}_{4}$ film or a $\mathrm{SiO}_{2}$ film at a room temperature. Raman shift of the reference which was a stress-free $\mathrm{Si}(100)$ substrate without a $\mathrm{Si}_{3} \mathrm{~N}_{4}$ cap was about $520.5 \mathrm{~cm}^{-1}$. Raman shift of $\mathrm{Si}(100)$ substrate with a $\mathrm{Si}_{3} \mathrm{~N}_{4}$ cap was larger than that of the reference and increased with the thickness of a $\mathrm{Si}_{3} \mathrm{~N}_{4}$ cap. The stress in $\mathrm{Si}(100)$ substrate estimated from an extra peak shift was $1.17 d \times 10^{9} \mathrm{dyn} / \mathrm{cm}^{2}$ when thickness of a $\mathrm{Si}_{3} \mathrm{~N}_{4}$ cap was $d \mu \mathrm{m}$. This value was 2 orders of magnitude larger than that estimated based on the bimetal model assuming that the stress was caused by difference of the thermal expansion coefficient between a $\mathrm{Si}_{3} \mathrm{~N}_{4}$ cap and $\mathrm{Si}(100)$ substrate. The compressive stress by a $\mathrm{Si}_{3} \mathrm{~N}_{4}$ cap was independent of a temperature because it was not due to difference of the thermal expansion coefficient but was due to the intrinsic stress in a $\mathrm{Si}_{3} \mathrm{~N}_{4}$ cap. ${ }^{7}$

It is considered that the introduced stress $\tau$ in an $a$-Si film was caused by the intrinsic stress in a $\mathrm{Si}_{3} \mathrm{~N}_{4}$ cap and that the quantity of the stress was almost the same as described above for $\mathrm{Si}(100)$ substrate. As shown in Fig. 3, stress in $\mathrm{Si}(100)$ substrate decreased rapidly with depth in the range of the penetration depth of the probe light $(514.5 \mathrm{~nm})$. The penetration depth in $a-\mathrm{Si}$ is an order of magnitude smaller than that of $c$-Si. Therefore, the stress in $a$-Si films was nearly constant within the range of the penetration depth of $a$-Si. In the measurement for $c$-Si, information from a region far from the surface of $\mathrm{Si}(100)$ substrate was included where stress no longer existed while in the case of $a$-Si, information

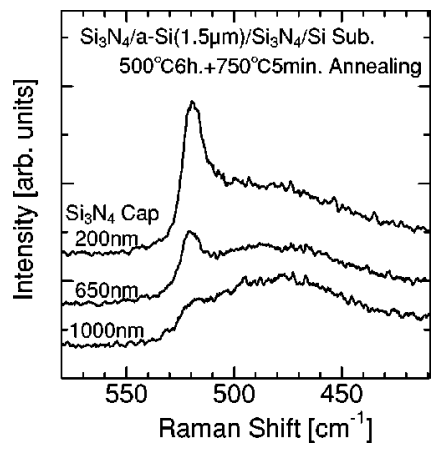

FIG. 4. Dependence of the Raman spectrum of the poly-Si film with a $\mathrm{Si}_{3} \mathrm{~N}_{4}$ cap on its thickness.

only from vicinity of the surface was included. Therefore, in order to estimate the stress in an $a$-Si film it is necessary to correct the value of stress estimated from the measurement for $c-\mathrm{Si}$ and the corrected value of stress $\tau$ was $2.54 d$ $\times 10^{9} \mathrm{dyn} / \mathrm{cm}^{2}$ when thickness of a $\mathrm{Si}_{3} \mathrm{~N}_{4}$ cap was $d \mu \mathrm{m}$. The strain $\epsilon$ in $a$-Si films due to a $\mathrm{Si}_{3} \mathrm{~N}_{4}$ cap of thickness $d$ $\mu \mathrm{m}$ is

$$
\epsilon=\frac{\tau}{K^{a-\mathrm{Si}}}=0.003 d,
$$

where $K$ is the elastic modulus. When the stress is biaxial $K$ is expressed by

$$
K=\frac{E}{1-\nu},
$$

where $E$ is Young's modulus and $\nu$ is Poisson ratio. The value of $E_{a \text {-Si }}$ for $a$-Si which contained no hydrogen has been reported as $(6.2 \pm 2.5) \times 10^{11} \mathrm{dyn} / \mathrm{cm}^{2}$ and 0.22 was used for $\nu{ }^{8,9}$ These values were used for $K^{a-\mathrm{Si}}$, as the $a-\mathrm{Si}$ films in this work was deposited by rf sputtering in an Ar atmosphere contained no hydrogen.

The density of $a$-Si increases with decrease in hydrogen concentration and that of $a$-Si which contains no hydrogen is very close to that of $c$-Si. ${ }^{9-11}$ Thus, volume change with crystallization is so small that it can be ignored in our experiment. Correspondingly, when crystalline fraction is very small the strain $\epsilon$ is nearly constant and the difference of the strain energy between $c$-Si and $a-\mathrm{Si} \Delta E_{\text {strain }}$ is given as follows:

$$
\Delta E_{\text {strain }}=\left(K_{c-\mathrm{Si}}-K_{a-\mathrm{Si}}\right) \epsilon^{2}
$$

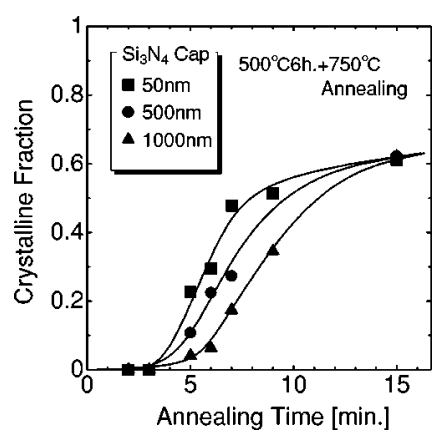

FIG. 5. The crystalline fraction of poly-Si vs annealing time. 


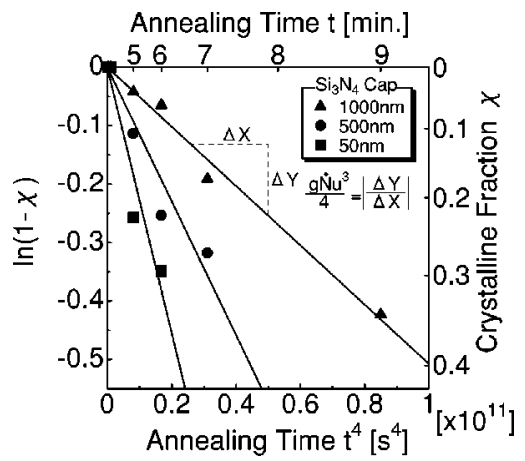

FIG. 6. Estimation of crystallization speed $g \dot{N} u^{3} / 4$ from crystalline fraction.

$$
=0.2 d^{2}[\mathrm{meV}],
$$

$K_{c-\mathrm{Si}}=2.290 \times 10^{12} \mathrm{dyn} / \mathrm{cm}^{2}$ was used in this work. $^{9,12}$ Thickness of a $\mathrm{Si}_{3} \mathrm{~N}_{4}$ cap $d$ is converted to $\Delta E_{\text {strain }}$ by this expression. In this case, it was assumed that the introduced stress did not relax. This assumption is the difference from the earlier model for crystallization under plastic stress and this leads to $\Delta E_{\text {strain }}>0$ because $c$-Si is stiffer than $a-\mathrm{Si}$ $\left(K_{c-\mathrm{Si}}>K_{a-\mathrm{Si}}\right)$. As a result, $\Delta F$ is smaller than $\Delta F_{0}$ and crystallization is suppressed.

Figure 4 shows the Raman spectra from $a$-Si films which were annealed with only a $\mathrm{Si}_{3} \mathrm{~N}_{4}$ cap at $750{ }^{\circ} \mathrm{C}$ for $5 \mathrm{~min}$ after annealing at $500^{\circ} \mathrm{C}$ for $6 \mathrm{~h}$. The spectrum consists of two peaks. One is around $520.5 \mathrm{~cm}^{-1}$ and is due to $c$-Si. The other is a broad peak around $480 \mathrm{~cm}^{-1}$ which is due to $a$-Si. Obviously, intensity of the Raman peak from $c$-Si decreased with thickness of a $\mathrm{Si}_{3} \mathrm{~N}_{4}$ cap. Figure 5 shows the crystalline fraction obtained from Raman spectra versus annealing time. The $a$-Si films with a thinner $\mathrm{Si}_{3} \mathrm{~N}_{4}$ cap crystallized faster than that with a thicker $\mathrm{Si}_{3} \mathrm{~N}_{4}$ cap. The crystalline fraction curve obtained form Raman spectra was not bound on the Johnson-Mehl expression at the stage where crystalline fraction is large, because the ratio of the scattering cross section $\gamma$ depends on grain size of poly-Si and because the JohnsonMehl expression explains only the early stage of crystallization. Therefore, crystallization speed $g \dot{N} u^{3} / 4$ was estimated from only the measurement points for a small crystalline fraction $(\chi<0.4), g \dot{N} u^{3} / 4$ is given by the gradient when $x$ axis is $\ln (1-\chi)$ and $y$ axis is $t^{4}$ as shown in Fig. 6. The linearity of data was very good and this meant that the

TABLE I. The comparison between the value obtained by fitting in this work and the values measured by other researchers. The order of magnitude of the interface energy can be estimated from the difference of surface energies.

\begin{tabular}{|c|c|c|c|c|}
\hline & \multirow{2}{*}{$\begin{array}{c}\text { Difference of free } \\
\text { energy } \Delta F_{0} \\
{[\mathrm{~kJ} / \mathrm{mol}]}\end{array}$} & \multirow{2}{*}{$\begin{array}{l}\text { Interface } \\
\text { energy } \sigma \\
{\left[\mathrm{erg} / \mathrm{cm}^{2}\right]}\end{array}$} & \multicolumn{2}{|c|}{$\begin{array}{c}\text { Surface energy } \\
{\left[\mathrm{erg} / \mathrm{cm}^{2}\right]}\end{array}$} \\
\hline & & & $\mathrm{Si}(111)$ & liquid $\mathrm{Si}$ \\
\hline This work & 8.1 & 476 & & \\
\hline Reference & $\begin{array}{l}9.9 \pm 1.2^{\mathrm{a}} \text { or } \\
11.6 \pm 0.7^{\mathrm{b}}\end{array}$ & 380 & $1240^{c}$ & $860^{c}$ \\
\hline
\end{tabular}

${ }^{\mathrm{a}}$ See Ref. 13.

${ }^{\mathrm{b}}$ See Ref. 14

${ }^{\mathrm{c}}$ See Ref. 15.

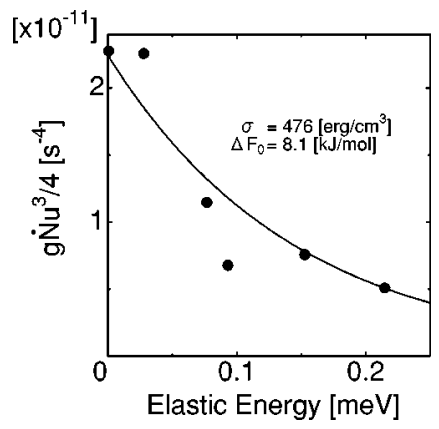

FIG. 7. The relation between the strain energy and crystallization speed $g \dot{N} u^{3} / 4$. The solid line is the result of fitting by the Eq. (8).

Johnson-Mehl expression was a good approximation at the early stage. Figure 7 shows the relation between $\Delta E_{\text {strain }}$ converted using the expression (13) and $g \dot{N} u^{3} / 4$ obtained from Fig. 6. The solid line was the result of fitting by the expression (8). The fitting parameters were a proportion constant, $\sigma$ and $\Delta F_{0}$, and the curve fitted the experimental data well. This indicates that the theory is a good approximation of crystallization under elastic stress. The values of $\sigma$ and $\Delta F_{0}$ obtained by fitting were $476 \mathrm{erg} / \mathrm{cm}^{2}$ and $8.1 \mathrm{~kJ} / \mathrm{mol}$, respectively. These values were close to the values measured by other researchers as shown in Table I. The difference of the enthalpy $\Delta H_{\mathrm{ac}}$ between $c$-Si and $a$-Si as a reference of $\Delta F_{0}$ is shown and it is the same as latent heat of crystallization. The surface energies of $c$-Si and liquid silicon are shown because data of the interface energy $\sigma$ between $a-\mathrm{Si}$ and $c-\mathrm{Si}$ could not been found. The order of magnitude of the interface energy $\sigma$ between $a$-Si and $c$-Si can be estimated from the difference of these.

The fact that measured data and the result of calculation showed good coincidence means that crystallization of an $a$-Si film under elastic stress can be explained by this model that elastic stress in an $a$-Si film does not relax with crystallization and that it suppresses crystallization.

\section{CONCLUSION}

Solid phase crystallization of an $a$-Si film under elastic stress was studied by laser Raman spectroscopy. It was found that the speed of crystallization can be controlled by the simple method in which thickness of a $\mathrm{Si}_{3} \mathrm{~N}_{4}$ cap on an $a-\mathrm{Si}$ film is adjusted. The crystallization was suppressed with increase of thickness of the $\mathrm{Si}_{3} \mathrm{~N}_{4}$ cap on $a$-Si films. It is likely that the elastic stress in an $a$-Si film does not relax with crystallization, which leads to a decrease in the difference of Helmholtz free energy between $a-\mathrm{Si}$ and $c-\mathrm{Si}$, as $c$-Si is stiffer than $a$-Si. As a result, crystallization was suppressed. The calculation by this model showed good coincidence with experimental results and the fitting parameters were close to the previously reported values.

\footnotetext{
${ }^{1}$ Y. Kimura and T. Katoda, J. Appl. Phys. 86, 2278 (1999).

${ }^{2}$ M. A. Johnson and R. F. Mehl, Trans. AIME 90, 416 (1939).

${ }^{3}$ M. Avrami, J. Chem. Phys. 7, 1103 (1939).

${ }^{4}$ M. Avrami, J. Chem. Phys. 8, 212 (1940).

${ }^{5}$ M. Avrami, J. Chem. Phys. 9, 177 (1941).

${ }^{6}$ R. Tsu, J. Gonzalez-Hernandez, S. S. Chao, S. C. Lee, and K. Tanaka, Appl. Phys. Lett. 40, 534 (1982).
} 
${ }^{7}$ M. Maeda and K. Ikeda, J. Appl. Phys. 83, 3865 (1998).

${ }^{8}$ Y. Tatsumi, M. Shigi, and M. Hirata, Jpn. J. Appl. Phys. 17, 1465 (1978).

${ }^{9}$ Properties of Amorphous Silicon, 2nd ed., EMIS Datareviews Series No.1 (INSPEC, The Institution of Electrical Engineers, London, 1989).

${ }^{10}$ E. C. Freeman and W. Paul, Phys. Rev. B 20, 716 (1979).

${ }^{11}$ I. Weitzel, R. Primig, and K. Kempter, Thin Solid Films 75, 143 (1981).
${ }^{12}$ W. A. Brantley, J. Appl. Phys. 44, 534 (1973).

${ }^{13}$ M. C. C. Fan and H. Andersen, J. Appl. Phys. 52, 4003 (1981).

${ }^{14}$ E. P. Donovan, F. Spaepen, and D. Turnbull, Appl. Phys. Lett. 42, 698 (1983).

${ }^{15}$ G. B. Samsonov, Svoistva Elementov (Moskva Metallurgya, 1976). 